\title{
Correction to: Sentinel node tumor burden in cutaneous melanoma. Survival with competing risk analysis and influence in relapses and non-sentinel node status: retrospective cohort study with long follow-up in a Spanish population
}

Leire Loidi-Pascual ${ }^{1}(1)$. Julián Librero ${ }^{2} \cdot$ Alicia Córdoba-Iturriagagoitia $^{3} \cdot$ Rosa Guarch-Troyas $^{3} \cdot$ Marta Montes-Díaz $^{3}$. Yerani Ruiz de Azua-Ciria ${ }^{3} \cdot$ Imanol Arozarena $^{4} \cdot$ Elena Goñi-Gironés $^{5} \cdot$ Ignacio Yanguas $^{1}$

Published online: 23 November 2021

(c) The Author(s), under exclusive licence to Springer-Verlag GmbH Germany, part of Springer Nature 2021

\section{Correction to: Archives of Dermatological Research https://doi.org/10.1007/s00403-021-02232-z}

In the original version of this article, the given and family names of all authors were incorrectly structured. The names were displayed correctly in all versions at the time of publication.

The original article has been corrected.
Publisher's Note Springer Nature remains neutral with regard to jurisdictional claims in published maps and institutional affiliations.

The original article can be found online at https://doi.org/10.1007/ s00403-021-02232-z.

Leire Loidi-Pascual

leyre.loidi.pascual@navarra.es

1 Dermatology Department of Complejo Hospitalario de Navarra, C/Irunlarrea., 31008 Pamplona, Navarra, Spain

2 Methodology Unit of Navarrabiomed Center-IDISNA, Pamplona, Spain

3 Pathology Department of Complejo Hospitalario de Navarra, Pamplona, Spain

4 Navarrabiomed, Complejo Hospitalario de Navarra, Instituto de Investigación Sanitaria de Navarra (IdiSNA), Pamplona, Spain

5 Nuclear Medicine Department of Complejo Hospitalario de Navarra, Pamplona, Spain 